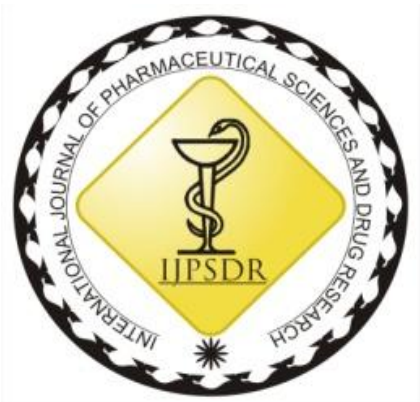

\author{
RESEARCH ARTICLE
}

ISSN: 0975-248X CODEN (USA): IJPSPP $(\mathrm{cc})$ EY-NC-SA

\title{
Development and Correlation between in vitro Drug Release and in vitro Permeation of Thermally Triggered Mucoadhesive in situ Nasal Gel of Repaglinide PVP K30 Complex
}

\author{
Kamla Pathak $^{1 *}$, Anil Kumar ${ }^{2}$, Ekta Yadav $^{2}$ \\ 1 Pharmacy College Saifai, Uttar Pradesh University of Medical Sciences, Etawah 206130, Uttar Pradesh, India \\ ${ }^{2}$ Department of Pharmaceutics, Rajiv Academy for Pharmacy, Mathura 281001, Uttar Pradesh, India
}

Copyright (C) 2019 Kamla Pathak et al. This is an open access article distributed under the terms of the Creative Commons AttributionNonCommercial-ShareAlike 4.0 International License which allows others to remix, tweak, and build upon the work non-commercially, as long as the author is credited and the new creations are licensed under the identical terms.

\begin{abstract}
The aim of the investigation was to develop and evaluate thermoreversible in situ nasal gel formulations of repaglinide (REP) and to establish correlation between its in vitro release and ex vivo permeation profiles. The solubility of REP was enhanced by preparing solid dispersions (SDs) with hydrophilic carriers (PVP K30/ PEG 6000/ poloxamer 188) in different weight ratios. REP: PVP K30 (1:5) was selected as the optimized SD as it showed highest enhancement in solubility (405\%). The optimized SD was characterized by SEM and DSC and incorporated into a blend of thermoreversible and mucoadhesive polymers (poloxamer 407 and carbopol $934 \mathrm{P}$ ) by cold technique to form in situ gels (F1-F6). The prepared in-situ gels were evaluated for various pharmacotechnical features and the formulation F3 exhibited least gelling time of $6.1 \pm 0.20$, good mucoadhesive property to ensure sufficient residence time at the site of application and a $\% \mathrm{CDR}$ of $82.25 \%$. The ex vivo permeation characteristics across goat mucosa can be summarized as CDP of $78.7 \%$, flux $=6.80 \mathrm{mg} / \mathrm{cm}^{2} / \mathrm{h}$; permeability coefficient of $2.02 \mathrm{mg} / \mathrm{h}$ and zero order kinetics. On correlating the CDR profile of F3 with that of its CDP profile, a $\mathrm{R}^{2}$ value of 0.991 (slope $=0.921$ ) was observed. The value of slope approximating one, suggested that almost entire amount of drug released from F3 was capable of permeating across the nasal mucosa, ex-vivo indicating that in-situ nasal gels of REP for systemic action can be successfully developed for the management non-insulin dependent type-II diabetes mellitus.
\end{abstract}

Keywords: Solid dispersion, nasal in-situ gel, in vitro release, permeation characteristics, correlation.

DOI: 10.25004/IJPSDR.2018.110104

Int. J. Pharm. Sci. Drug Res. 2019; 11(1): 22-30

*Corresponding author: Dr. Kamla Pathak

Address: Pharmacy College Saifai, Uttar Pradesh University of Medical Sciences, Etawah 206130, Uttar Pradesh, India

Tel.: +91-9897612318

E-mail $\bowtie$ : kamlapathak5@gmail.com

Relevant conflicts of interest/financial disclosures: The authors declare that the research was conducted in the absence of any commercial or financial relationships that could be construed as a potential conflict of interest.

Received: 31 October, 2018; Revised: 27 November, 2018; Accepted: 28 December, 2018; Published: 20 January, 2019

\section{INTRODUCTION}

The nasal mucosa is considered as an administration route that favours faster and higher level of drug absorption due to its porous endothelial membrane, large surface area, and high total blood flow. ${ }^{[1-2]}$ The nasal cavity offers a number of advantages such as easy accessibility, optimal permeability for lipophilic and low molecular weight drugs, and avoidance of both harsh gastrointestinal milieu and hepatic first pass metabolism. [3-4] 
Repaglinide (REP) is a meglitinide phenylalanine analogue (2-ethoxy-4-(\{[(1S)-3-methyl-1-[2-(piperidin-1yl) phenyl] butyl] carbonyl\} methyl) benzoic acid) used an oral antidiabetic for the treatment of type II (noninsulin dependent) diabetes mellitus. It acts primarily by decreasing insulin resistance. A BCS class II, is a highly lipophilic molecule with partition coefficient $(\log \mathrm{P})$ of 5.9, poor dissolution properties, presents poor oral bioavailability of 50\%. [5-6] Although REP is rapidly absorbed after oral administration, it is critical to improve the dissolution rate of REP in order to enhance bioavailability due to its low solubility. ${ }^{[7]}$ REP induces rapid onset of short-lasting insulin release. It is administered before each meal to control postprandial hyperglycemia. ${ }^{[8]}$ Poor solubility in gastrointestinal fluids causes variations in its dissolution rate which leads to incomplete bioavailability. ${ }^{[9]}$ Hence in the current project an attempt was made to increase the solubility of the drug by solid dispersion technique. The effects of hydrophilic carriers on enhancement in solubility of the drug were investigated and the optimized SD was selected. The optimized SD was then incorporated into the mucoadhesive in-situ gel for nasal delivery with aim to overcome the limitations associated with oral administration.

REP is commercially available as tablets and capsules, alone and in combination with metformin. [8] A plethora of reports on developing effective delivery systems can be found in the scientific literature. Polymeric nanoparticles of REP were developed using ethyl cellulose by solvent evaporation method in order to obtain a novel delivery system adequate for the treatment of diabetes. [10] Floating multiparticulate system of beta cyclodextrin complexed REP was prepared by melt granulation method using gelucire 43/01 as a binder. [11] In another research report solid matrix tablet of REP was formulated using sodium alginate, sodium CMC and PVP and evaluated for controlled drug release of the drug. [12] Though these reports claim superiority over the conventional formulations, the drug related gastrointestinal adverse effects and extensive hepatic metabolism on oral administration cannot be ignored.

Nasal route can serve as an alternate delivery route to obviate the gastrointestinal side effects. In-situ nasal gel formulations offer an alternative for achieving systemic drug effects of parenteral route. It also promotes the easy and convenient deliverance of accurate dose as well as prolongs residence time of drug in contact with mucosa. The favorable features of the drug and not a single report on its intranasal delivery guided us for developing an in-situ nasal gel of REP that would avoid hepatic metabolism as well the adverse effects associated with drug on oral administration.

\section{MATERIALS AND METHODS}

REP was a kind gift from Sun Pharmaceuticals, Andaman and Nicobar, India. Poloxamer 407 and Carbopol 934 were procured from BASF Corporation,
USA and CDH Pvt. Ltd., New Delhi, India. The chemicals supplied by SD Fine Chem Ltd., Mumbai, India are PVP K 30, poloxamer 188, polyethylene glycol (PEG) 6000, methanol and potassium dihydrogen orthophosphate.

\begin{tabular}{|c|c|c|c|c|c|}
\hline Code & Carrier & $\begin{array}{c}\text { Drug: } \\
\text { carrier } \\
\text { (by weight) }\end{array}$ & $\begin{array}{c}\text { Solubility } \\
(\mathrm{mg} / \mathrm{ml})\end{array}$ & $\begin{array}{c}\text { Enhancement } \\
\text { in solubility } \\
(\%)\end{array}$ & $\begin{array}{c}\text { Drug } \\
\text { content } \\
(\%)\end{array}$ \\
\hline REP & -- & -- & 0.037 & - & - \\
\hline SD1 & $\begin{array}{c}\text { Poloxamer } \\
188\end{array}$ & 1:1 & 0.087 & 136 & $90.1 \pm 1.50$ \\
\hline SD2 & $\begin{array}{c}\text { Poloxamer } \\
188\end{array}$ & $1: 3$ & 0.125 & 237 & $86.0 \pm 1.32$ \\
\hline SD3 & $\begin{array}{c}\text { Poloxamer } \\
188\end{array}$ & $1: 5$ & 0.162 & 337 & $82.3 \pm 1.04$ \\
\hline SD4 & PEG 6000 & $1: 1$ & 0.050 & 35 & $82.0 \pm 1.32$ \\
\hline SD5 & PEG 6000 & $1: 3$ & 0.112 & 202 & $78.8 \pm 1.25$ \\
\hline SD6 & PEG 6000 & $1: 5$ & 0.125 & 237 & $80.8 \pm 0.76$ \\
\hline SD7 & PVP K 30 & 1:1 & 0.100 & 170 & $94.5 \pm 1.80$ \\
\hline SD8 & PVP K 30 & $1: 3$ & 0.150 & 305 & $96.5 \pm 0.45$ \\
\hline SD9 & PVP K 30 & $1: 5$ & 0.187 & 405 & $98.4 \pm 0.51$ \\
\hline
\end{tabular}

\section{Preparation of solid dispersions}

The solid dispersions of REP with PVP K30 were prepared by solvent evaporation method while the solid dispersions with PEG6000 and poloxamer 188 were prepared by melting method. For the former, REP and PVP K30 were taken in different weight ratios (1:1, 1:3, and 1:5). The mixtures were triturated and dissolved in methanol. The solution was evaporated at $40^{\circ} \mathrm{C}$ and the residual mass was scraped and sifted through sieve \# 120 and stored in a dessicator for drying. The composition is given in the Table 1. In melting method, PEG 6000 was melted in a water bath at $70^{\circ} \mathrm{C}$. REP was added in the solid state and the mixture was stirred well until homogeneity was attained. The mixture was allowed to cool slowly at room temperature $25^{\circ} \mathrm{C}$, and then pulverized in a glass mortar. The pulverized mass was sifted through a sieve No. 120 and kept in a dessicator for drying. The same procedure was repeated for Poloxamer 188, where the polymer was melted at temperature of $55^{\circ} \mathrm{C}$. The solid dispersions were stored in a dessicator until use for drug content analysis and equilibrium solubility.

\section{Drug content}

Solid dispersion theoretically equivalent to $2 \mathrm{mg}$ of REP was weighed accurately and dissolved in $2 \mathrm{ml}$ of methanol. The stock solution was diluted with distilled water to make up the final volume up to $10 \mathrm{ml}$ and analyzed spectrophotometerically (UV spectrophotometer, Shimadzu Pharmaspec 1700, Kyoto, Japan) at $281 \mathrm{~nm}$.

Equilibrium solubility

To assess the solubility of drug, an excess amount of REP and its solid dispersion(s) with PVP K 30/ PEG $6000 /$ poloxamer 188 were added separately to $10 \mathrm{ml}$ of distilled water in a conical flask and agitated on a water bath shaker (Hicon Enterprises, New Delhi, India) maintained at $37 \pm 0.5^{\circ} \mathrm{C}$. The flasks were shaken for 72 $\mathrm{h}$ and thereafter, the samples were withdrawn, filtered through membrane filter $(0.45 \mu)$ and analyzed spectrophotometrically. The optimized solid dispersion 
was selected on the basis of maximum enhancement in the solubility of REP and characterized by scanning electron microscopy and differential scanning calorimetry.

\section{Scanning Electron Microscopy}

The surface morphology was studied by scanning electron microscope (JEOL 5400 Tokyo, Japan). The samples were adhered on a double-sided tape stuck to aluminum stub. The stubs were then coated with gold ion by sputter coater unit under an argon atmosphere in order to make them conductive. The micrographs were visualized under $2.96 \mathrm{KX}$ magnification.

\section{Differential Scanning Calorimetry}

Differential scanning thermograms of REP, PVP K 30, and optimized solid dispersion were obtained using a DSC Q-200 V 24.4, USA. Thermal behaviours were studied with samples sealed (5 to $10 \mathrm{mg}$ sample) in aluminium pans and under a nitrogen gas flow of 20 $\mathrm{ml} / \mathrm{min}$. The heating rate of samples was $10^{\circ} \mathrm{C} / \mathrm{min}$ over a temperature range of $60-200^{\circ} \mathrm{C}$.

\section{In situ nasal gel}

The optimized solid dispersion was developed as in situ nasal gel. A formulation design comprising of six formulations was used to optimize thermosensitive mucoadhesive in-situ nasal gel formulation. The amount of poloxamer 407 (thermosensitive), and carbopol 934 P (mucoadhesive polymer) was varied at three levels (low, medium and high) to analyze the gelling and mucoadhesive characteristics of the formulated in situ gels. As the in situ gel was aimed at sustaining the drug release for $12 \mathrm{~h}$, accordingly the REP dose to achieve the same was calculated.

\section{Dose calculation for sustained release}

The dose for sustained release of the drug from in situ nasal gel was calculated using the following equation:

$$
\mathrm{D}_{\mathrm{T}}=\mathrm{Do}\left(1+0.693 \mathrm{t} / \mathrm{t}_{1 / 2}\right) \ldots \ldots \text {..Eq.1 }
$$

Do = conventional dose of REP (2- $4 \mathrm{mg} 4$ times a day); $\mathrm{t}=$ Time duration for sustained release $(12 \mathrm{~h})$ and $\mathrm{t}_{1 / 2}=$ half-life of REP $(1 \mathrm{~h})$. $\mathrm{D}_{\mathrm{T}}$ was calculated as $18.6 \mathrm{mg}$ that was rounded off to $19 \mathrm{mg}$ for handling purpose.

Preparation of thermally triggered mucoadhesive insitu nasal gel

In-situ nasal gel gels were prepared by the cold method described by Schmolka. [13] An amount of SD9 equivalent to $19 \mathrm{mg}$ of REP was mixed with carbopol $934 \mathrm{P}$ and stirred with $50 \mathrm{ml}$ of distilled water at room temperature. The dispersions were then cooled to $4^{\circ} \mathrm{C}$ by storing in a refrigerator for $3 \mathrm{~h}$. Poloxamer 407 was added slowly with continuous stirring on a thermostatically controlled magnetic stirrer maintained at $4^{\circ} \mathrm{C}$. The dispersions were then stored in a refrigerator overnight to get clear sols. The formulations were stored in a refrigerator so that they remain in sol form and evaluated for the parameters detailed below.

\section{Evaluation}

\section{Clarity}

The clarity of all formulations (F1-F6) was determined by visual inspection under black and white background.

\section{pH and viscosity of sol}

One $\mathrm{ml}$ of each formulation was transferred to the 10 $\mathrm{ml}$ volumetric flask and diluted with distilled water to make volume up to $10 \mathrm{ml}$. The $\mathrm{pH}$ of the resulting solution was determined by calibrated $\mathrm{pH}$ meter. The viscosity of each sol was measured using Brookfield viscometer DVII+ Pro coupled with S-94 spindle at 100 rpm at $4 \pm 1^{\circ} \mathrm{C}$.

\section{Drug content}

One $\mathrm{ml}$ of each formulation was extracted with $1 \mathrm{ml}$ of methanol by vortexing. Appropriate dilutions were made with phosphate buffer, $\mathrm{pH} 6.4$ and assayed.

\section{Gelling temperature and time}

The gelling temperature of the formulation was determined by method described by Miller and Donovan. [14] Two $\mathrm{ml}$ of aliquot of each formulation was taken in a test tube, immersed in a water bath. The temperature of water bath was increased in increments of $1^{\circ} \mathrm{C}$ and left to equilibrate for $5 \mathrm{~min}$ at each new increment. The samples were observed for gelation which was said to have occurred when the meniscus would no longer flow upon tilting through $90^{\circ}$. Gelling time was recorded as the time for first detection of gelation.

\section{Gel strength}

The gel strength was measured by the method described in literature. [15] The property was quantitated determined by placing $50 \mathrm{~g}$ of formulation in a $100 \mathrm{ml}$ graduated cylinder and gelled at $37^{\circ} \mathrm{C}$ using thermostat. A weight of $35 \mathrm{~g}$ was placed onto the gelled solution and allowed to penetrate $5 \mathrm{~cm}$ in the gel. Time taken by the weight to penetrate $5 \mathrm{~cm}$ was measured.

\section{Ex-vivo mucoadhesive strength}

Ex-vivo mucoadhesive strength was determined by modified balance method using the freshly excised goat nasal mucosa. The two sides of the balance were balanced by placing a beaker on the right hand pan and $5 \mathrm{~g}$ weight on the left hand pan. A piece of $\left(1 \times 1 \mathrm{~cm}^{2}\right)$ of goat nasal mucosa was fixed with cyanoacrylate glue over inverted beaker which was covered with inert aluminium surface. The assembly was lowered into the glass beaker filled with phosphate buffer, $\mathrm{pH} 6.4$ to keep the mucosa moist and kept underneath the left hand side of the balance. One gram of the gel was spread as a thin film (thickness $2 \mathrm{~mm}$ ) on the lower surface of the left hand pan of the balance. Beaker was removed from the right hand pan which lowered the left hand pan along with the gel. The balance was kept in this position for 2 min contact time. The beaker was replaced on the right hand pan and water was gradually added from burette at the rate of 100 drops/min to the beaker over right hand pan until the mucosal membrane detached from the gel surface. [16] The mucoadhesive force expressed as the detachment stress in dynes $/ \mathrm{cm}^{2}$ was determined from the minimal weight that detached the mucosal tissue from surface of each formulation.

Mucoadhesive strength $\left(\right.$ dynes $\left./ \mathrm{cm}^{2}\right)=\mathrm{m} \mathrm{g} / \mathrm{A}$....Eq. 2 
Where, $\mathrm{m}=$ mass required for detachment in gram, $\mathrm{A}=$ Area of mucosa exposed, and $\mathrm{g}=$ Acceleration due to gravity $\left(980 \mathrm{~cm} / \mathrm{s}^{2}\right)$. The nasal mucosa was changed for each measurement

\section{In vitro release}

The in vitro release drug from sol was carried out using fabricated Franz diffusion cell consisting of donor and receptor compartment separated by dialysis membrane of pore size $0.22 \mu \mathrm{m}$ (Himedia Ltd., Mumbai,). Formulation equivalent to $2 \mathrm{mg} / \mathrm{ml}$ REP was placed in donor compartment and receptor compartment was filled with phosphate buffer, $\mathrm{pH} 6.4$ and constantly stirred using magnetic stirrer. The donor and receptor chambers were separated by dialysis membrane soaked in receptor medium overnight prior to experiment. The temperature was maintained at $37 \pm 1.0^{\circ} \mathrm{C}$ in order to simulate body conditions. One $\mathrm{ml}$ sample from receptor chamber was withdrawn at predetermined time intervals replacing the withdrawn sample with fresh phosphate buffer, $\mathrm{pH} 6.4$ after each sampling for $12 \mathrm{~h}$. The samples were analyzed spectrophotometrically at $281 \mathrm{~nm}$. Graph was plotted between the cumulative drug release versus time to analyze the release characteristics.

\section{Ex vivo permeation}

The ex vivo permeation study of all the formulations and pure drug suspension was performed using Franz diffusion cell using goat nasal mucosa. The nasal mucosa was obtained from local butcher shop immediately after the animal was slaughtered and transferred into phosphate buffer, $\mathrm{pH} 6.4$ within one hour of slaughtering. The nasal conch was collected and washed with phosphate buffer, $\mathrm{pH}$ 6.4. The extraneous tissues were removed to get the mucosa. The donor compartment was filled with formulation equivalent to $2 \mathrm{mg}$ of REP and the receptor compartment was filled with $10 \mathrm{ml}$ of freshly prepared phosphate buffer, pH 6.4 and stirred continuously with magnetic bar. The donor and receptor compartment was separated by nasal mucosa (area $0.785 \mathrm{~cm}^{2}$ ) in such a way that its epithelial surface faced the donor compartment. The whole assembly was maintained at $37 \pm 0.5^{\circ} \mathrm{C}$. One $\mathrm{ml}$ sample was withdrawn from the receptor chamber and replaced with an equal volume of phosphate buffer, $\mathrm{pH} 6.4$ at predetermined time points of $0,1,2,4,6,8,10,12 \mathrm{~h}$. The samples were analyzed for the amount of drug permeated at $281 \mathrm{~nm}$. Graphs were plotted between percent cumulative drug permeated against time. Flux (Jss) was calculated as the slope of steady state portion of the plot $(\mathrm{mg} / \mathrm{h})$ between cumulative amount of drug permeated versus time.

Permeability coefficient $(\mathrm{Kp})=\mathrm{Jss} / \mathrm{Co} \quad \ldots . .$. Eq. 3

Where; Jss = steady state flux $\left(\mu \mathrm{g} / \mathrm{cm}^{2} / \mathrm{h}\right)$, Co $=$ total donor concentration of the formulation $(\mathrm{mg})$

$$
\text { Target flux }\left(\mathrm{J}_{\text {Target }}\right)=\mathrm{Css} \mathrm{Cl} \text { BW/A ....Eq.4 }
$$

BW represents the standard human body weight (70 $\mathrm{kg})$, A represents the surface area of nasal mucosa used for the permeation study, Css is the therapeutic concentration of REP $(2-4 \mu \mathrm{g} / \mathrm{L})$ and $\mathrm{Cl}$ the total clearance. For calculation the average values of both Css and $\mathrm{Cl}$ were taken. ${ }^{[17]}$ The calculated J $\mathrm{J}_{\text {Target }}$ for REP was calculated as $0.78\left(\mu \mathrm{g} / \mathrm{cm}^{2} / \mathrm{h}\right)$. Permeation kinetics of each formulation was determined by subjecting the data to various models (Zero, First, Higuchi model). Additionally, graphical correlation between in-vitro drug release and ex-vivo drug permeation was established by linear regression.

Selection of optimized gel

The optimized formulation was selected on the basis of least gelling temperature, highest mucoadhesive strength and highest percent cumulative drug permeated after $12 \mathrm{~h}$.

\section{Histological evaluation}

The tissue used for ex vivo permeation study was compared with freshly collected nasal mucosa incubated with phosphate buffer, $\mathrm{pH} 6.4$ to assess histological change if any. After permeation study, the nasal mucosa was cleared off the gel, fixed in 10\% buffered formalin, $\mathrm{pH}$ 7.2, routinely processed and embedded in paraffin. The paraffin sections were stained with hematoxylin and eosin. The samples were observed through photomicroscope (Hicon enterprises, New Delhi, India) at 1000X magnification.

\section{Stability}

For the assessment of stability of the optimized in-situ gel of REP (F3), was stored in a sealed glass vial at $40^{\circ} \mathrm{C} / 75 \%$ relative humidity in the stability chamber for 3 months. The samples were withdrawn at predetermined time intervals of $0,1,2$ and 3 months and observed for physical stability, drug content and ex-vivo drug permeation characteristics. The results were supported by statistical analysis using ANOVA (significance level $p<0.05$ ).

\section{RESULT AND DISCUSSION \\ Solid dispersion}

REP, a BCS class II drug is a poorly soluble drug with good permeability characteristics. Poor solubility causes the drug to dissolve very slowly in the gastrointestinal tract, thereby leading to poor dissolution and hence poor bioavailability. Solid dispersion is a firmly established as a platform technology for improving solubility of poorly soluble drugs. The solid dispersions of REP were prepared using inexpensive and easily available hydrophilic carriers PEG 6000, Poloxamer 188 and PVP K 30 to enhance its solubility. The solid dispersions were free flowing, white powders with drug content in the range of $78.8 \pm 1.25$ to $98.4 \pm 0.51$ (Table 1). Highest drug content was recorded for solid dispersions prepared with PVPK30 (94.5 $\pm 1.80-98.4 \pm 0.51 \%)$ followed by those prepared with poloxamer188 and least for PEG6000 solid dispersions. Clearly the solid dispersions prepared by solvent evaporation method showed higher drug content than fusion method. 
Low values of standard deviation indicated that the drug was uniformly dispersed in the formulation.

\section{Equilibrium solubility}

The solubility of REP in double distilled water was found to be $0.037 \mathrm{mg} / \mathrm{ml}$ whereas the solubility of its solid dispersions ranged from 0.100 to $0.187 \mathrm{mg} / \mathrm{ml}$. The enhancement in solubility widely ranged from 35 to $405 \%$ as given in Table 1 . The reasons attributable are the inherent differences between the carriers in terms of hydration, dissolution and complexation mechanisms of drug with different carriers. [18] The rank order in descending manner was PVPK30> poloxamer 188> PEG6000. Furthermore, the enhancement in solubility of REP was corelatable to the amount of carrier used. Thus it increased with increasing amount of carrier by a factor of $\geq 1.86$ ) in the levels used in the study. As explained in the literature the solubility enhancement in solid dispersion is based on the phenomenon of drug entrapment within the dispersion matrix at molecular level. Since a solid dispersion is a drug-polymer two component system, the drug-polymer interaction is the determining factor in its performance. ${ }^{[19]}$ Based on the maximum enhancement in the solubility of REP with PVP K30 in the ratio of 1:5, SD9 was selected as the optimized formulation.

\section{Scanning Electron Microscopy}

In order to deduce the physical state of the optimized solid dispersion scanning electron microscopy was carried out against reference sample. REP appeared as regular three dimensional crystals (Fig 1a) while PVP K 30 appeared as three dimensional globular particles (Fig 1b). In the micrograph of SD9 (Fig. 1c) the original morphology of both the individual components disappeared and an amorphous product was generated which proved the formation of solid dispersion.

\section{Differential Scanning Calorimetry}

The DSC thermogram of REP displayed a sharp endothermic peak at $127^{\circ} \mathrm{C}(\Delta \mathrm{H}$ of $118.57 \mathrm{~J} / \mathrm{g})$ due to melting of REP (Fig. 2a) which is consistent with literature report. [17] For PVP K 30 one broad endothermic peak at $118^{\circ} \mathrm{C}(\Delta \mathrm{H}$ of $258.26 \mathrm{~J} / \mathrm{g})$ was observed due to dehydration (Fig. 2b). In the thermogram of SD9 (Fig. 2c), the peak of REP did not disappear rather a slight shift towards the lower temperature at $123^{\circ} \mathrm{C}(\Delta \mathrm{H}$ of $106.03 \mathrm{~J} / \mathrm{g})$ was seen with reduced intensity of the peak along with the peak of
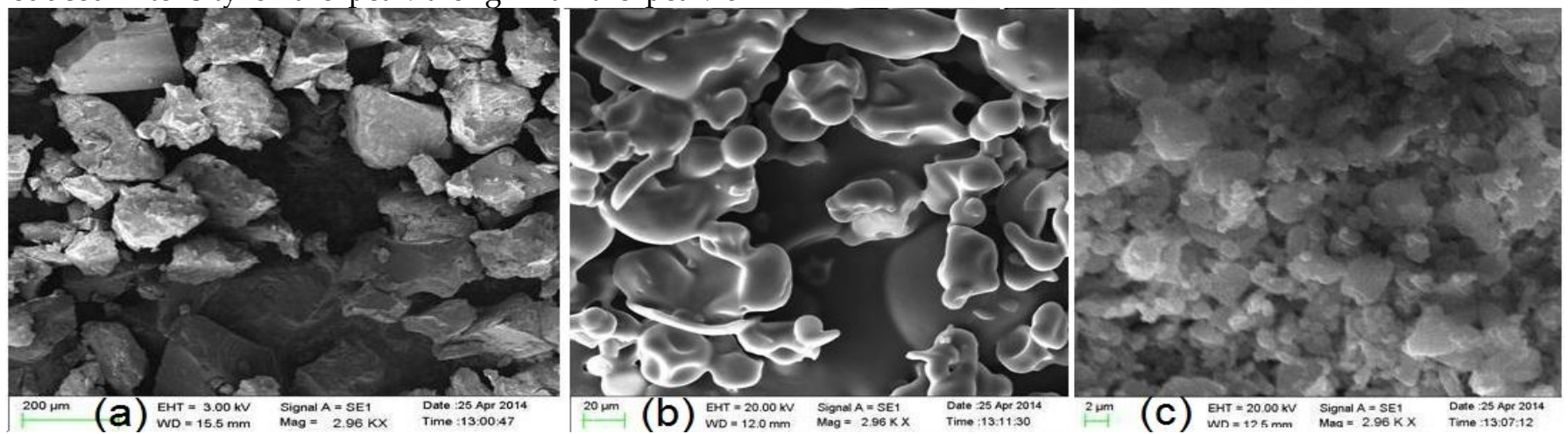

PVP K 30 at $78^{\circ} \mathrm{C}(\Delta \mathrm{H}$ of $101.65 \mathrm{~J} / \mathrm{g})$. The shift toward the lower temperature was the result of mixing of two components implying that REP was included into the PVP K 30 and partial amorphization. This confirmed the formation of solid dispersion of REP, a product of reduced crystallanity.

Thermally triggered mucoadhesive in situ nasal gel Six formulations (F1-F6) of thermally triggered mucoadhesive in situ were successfully prepared by cold method using poloxamer as gelling agent and carbopol as mucoadhesive agent. The formulations appeared as translucent sols with faint odour of raw materials. The formulations were evaluated for various parameters and the results are discussed below.

\section{Clarity and Drug content}

All the formulations were found to be free from solid residue matter that could potentially harm the nasal mucosa and affect the syringability of the formulations. The drug content of all the formulations ranged between $83.24 \pm 0.43-94.38 \pm 0.25 \%$ (Table 2 ).

$\mathrm{pH}$ and viscosity of sol

Nasal mucosa being a delicate organ, $\mathrm{pH}$ is a very important consideration for formulations intended for nasal application. The normal physiological $\mathrm{pH}$ of the nasal mucosa ranges from 4.5-6.5. But the nasal mucosa has the capability to tolerate extreme $\mathrm{pH}$ range from 3 narrowly varied from 5.42-5.79 (Table 2) which is well within the desirable range and thus the formulations can be presumed to be free from nasal irritation. While an alkaline $\mathrm{pH}$ inactivates lysozyme secreted by the nasal cells making the nasal tissue susceptible to microbial infection; lower $\mathrm{pH}$ acts as hypertonic solution that causes shrinkage of epithelial cells and also inhibits ciliary activity in the nasal cavity. [21] The viscosity of the formulations ranged from $27.44 \pm 0.34$ to $42.17 \pm 0.11 \mathrm{cp}$. Increase in the carbopol 934P content increased the viscosity of sols. The sol formulations should have an optimum viscosity, which would facilitate easy instillation into the nasal cavity wherein it will then undergo rapid sol to gel conversion. Viscosity plays an important role in a nasal formulation as it helps in increasing the residence time of the formulation by decreasing the mucociliary clearance. ${ }^{22]}$ to 10. [20] The $\mathrm{pH}$ of all the formulations (F1-F6)

Fig. 1: Scanning electron micrographs of (a) REP (b) PVP K 30 and (c) SD9. 
Kamla Pathak et al. / Thermally Triggered Mucoadhesive in situ Nasal Gel of Repaglinide PVP K30 Complex

Table 2: Formulation design and evaluation parameters of thermoreversible mucoadhesive formulations of in-situ gel of REP solid dispersion containing 140 mg of SD9.

\begin{tabular}{|c|c|c|c|c|c|c|c|c|c|}
\hline Code & $\begin{array}{c}\text { Poloxamer } \\
407 \\
(\% \mathrm{w} / \mathrm{v}) \\
\end{array}$ & $\begin{array}{c}\text { Carbopo } \\
1934 P \\
(\% \mathrm{w} / \mathrm{v})\end{array}$ & $\begin{array}{c}\text { pH } \\
\pm \text { S.D }\end{array}$ & $\begin{array}{c}\text { Gelling } \\
\text { temp. }\left({ }^{\circ} \mathrm{C}\right) \\
\pm \text { S.D }\end{array}$ & $\begin{array}{l}\text { Gelling time } \\
\text { (sec) } \pm \text { S.D }\end{array}$ & $\begin{array}{l}\text { Viscosity of sol } \\
\text { (cps) } \pm \text { S.D }\end{array}$ & $\begin{array}{l}\text { Drug content } \\
(\%) \pm \text { S.D }\end{array}$ & $\begin{array}{l}\text { Gel strength (sec) } \\
\pm \text { S.D }\end{array}$ & $\begin{array}{c}\text { Ex vivo mucoadhesive } \\
\text { strength }\left(\text { dynes } / \mathrm{cm}^{2}\right) \pm \\
\text { S.D }\end{array}$ \\
\hline F1 & 15 & 0.25 & $5.79 \pm 0.01$ & $35.24 \pm 0.04$ & $16.61 \pm 0.25$ & $29.63 \pm 0.34$ & $85.46 \pm 0.25$ & $29.54 \pm 0.50$ & $3295.13 \pm 0.71$ \\
\hline F2 & 25 & 0.50 & $5.61 \pm 0.04$ & $34.00 \pm 0.01$ & $13.73 \pm 0.25$ & $28.23 \pm 0.11$ & $89.16 \pm 0.37$ & $25.86 \pm 0.76$ & $3550.24 \pm 0.34$ \\
\hline F3 & 30 & 1.0 & $5.42 \pm 0.02$ & $29.42 \pm 0.11$ & $6.13 \pm 0.20$ & $42.17 \pm 0.11$ & $94.38 \pm 0.25$ & $47.02 \pm 0.45$ & $6432.44 \pm 0.83$ \\
\hline F4 & 15 & 1.0 & $5.69 \pm 0.01$ & $31.48 \pm 0.02$ & $11.86 \pm 0.2$ & $38.36 \pm 0.17$ & $90.56 \pm 0.41$ & $40.72 \pm 0.11$ & $6104.92 \pm 0.56$ \\
\hline F5 & 25 & 0.25 & $5.74 \pm 0.01$ & $30.60 \pm 0.02$ & $10.14 \pm 0.26$ & $27.44 \pm 0.34$ & $83.24 \pm 0.43$ & $32.44 \pm 0.11$ & $4386.78 \pm 1.26$ \\
\hline F6 & 30 & 0.50 & $5.67 \pm 0.01$ & $32.01 \pm 0.01$ & $12.47 \pm 0.11$ & $37.15 \pm 0.15$ & $88.73 \pm 0.40$ & $38.76 \pm 0.15$ & $4738.59 \pm 0.76$ \\
\hline
\end{tabular}

Table 3: Ex-vivo permeability parameters of in situ nasal gel of REP across goat nasal mucosa

\begin{tabular}{|c|c|c|c|c|c|c|}
\hline Code & $\begin{array}{l}\% \text { Cumulative drug } \\
\text { permeated }(12 \mathrm{~h})\end{array}$ & Flux $\left(J_{\mathrm{ss}}\right)\left(\mathrm{mg} / \mathrm{cm}^{2} / \mathrm{h}\right)$ & Enhancement ratio & $\begin{array}{l}\text { Permeability coefficient }\left(\mathrm{K}_{\mathrm{p}}\right) \\
(\mathrm{cm} / \mathrm{h})\end{array}$ & Best fit model & $\mathbf{R}^{2}$ \\
\hline REP & $18.84 \pm 0.34$ & 3.36 & - & 1.68 & Higuchi & 0.9492 \\
\hline F1 & $58.94 \pm 0.91$ & 6.05 & 1.80 & 2.43 & Zero order & 0.9690 \\
\hline $\mathrm{F} 2$ & $63.42 \pm 0.84$ & 6.80 & 2.02 & 3.40 & Higuchi & 0.9766 \\
\hline F3 & $78.73 \pm 0.37$ & 9.90 & 2.94 & 5.01 & Zero order & 0.9913 \\
\hline $\mathrm{F} 4$ & $74.26 \pm 0.48$ & 4.05 & 1.20 & 2.02 & Zero order & 0.9902 \\
\hline F5 & $67.53 \pm 0.71$ & 5.85 & 1.74 & 2.92 & Zero order & 0.9931 \\
\hline F6 & $71.58 \pm 0.53$ & 5.37 & 1.59 & 2.68 & Higuchi & 0.9904 \\
\hline
\end{tabular}

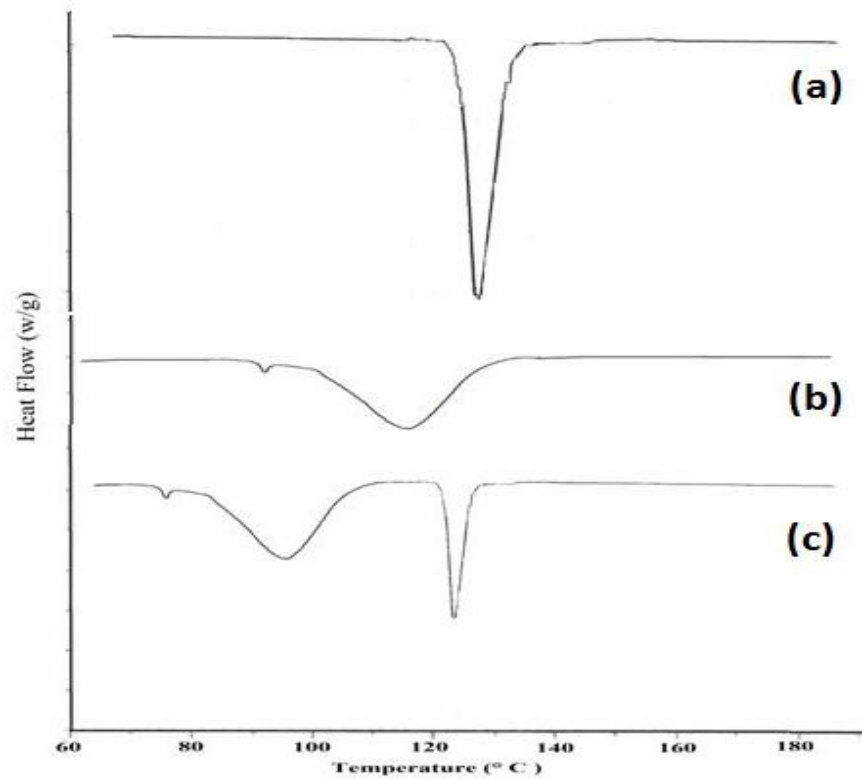

Fig. 2: DSC thermograms of (a) REP (b) PVP K 30 and (c) SD9.

\section{Gelling temperature and time}

The gelling temperature of the formulations ranged from $29.42 \pm 0.11-35.24 \pm 0.04^{\circ} \mathrm{C}$ (Table 2). A gelling temperature is considered to be suitable if it is in the range of $25^{\circ} \mathrm{C}$ to $37^{\circ} \mathrm{C}$. At gelling temperature lower than $25^{\circ} \mathrm{C}$, a gel might be formed at room temperature leading to difficulty in manufacturing, handling and administering, and if it is higher than $37^{\circ} \mathrm{C}$, it would not form gel at the temperature of nasal cavity so would result in rapid nasal clearance of administered formulation. [23] The formation of gel may be explained as formation of micelles. When the temperature is increased the micelles formation increases due to negative coefficient of solubility of block copolymer micelles. The micelles become so tightly packed that the solution becomes immobile and gel is formed. [24] Our results revealed that gelling temperature decreased with increase in the concentration of thermosensitive polymer poloxamer 407 due to formation of larger number of the micelles. [25] The mucoadhesive agent carbopol $934 \mathrm{P}$ also causes lowering of gelling temperature because of its ability to bind to poly(ethylene) oxide chains present in poloxamer 407 molecule, thus promoting dehydration and causing an increase in entanglement of adjacent molecule with extensive intermolecular $\mathrm{H}$-bonding thus enhancing micellar association. [23] Immediate gelling increases residence time and enhances bioavailability of drug. All the formulations gelled rapidly. The gelling time of the formulations ranged between $6.13 \pm 0.20$ to $16.61 \pm 0.25$. Lowest value was recorded for F3 that was constituted of maximum levels of poloxamer 407 and carbopol 934P.

\section{Gel strength}

The gel strength of the formulations was between 29.54 \pm 0.50 and $47.02 \pm 0.45$ (Table 2) which is acceptable for nasal delivery as the gel strength values in between 2550 are considered optimal. A gel strength of less than 25 would not be able to maintain gel integrity and may erode rapidly while gels with strength greater than 50 are too stiff and have potential to cause discomfort to the mucosal surfaces or may damage it. [26] Among the developed formulations, F3 showed highest gel strength of 47.02 while F1 showed least gel strength of 29.54. F3 composed of highest levels of both poloxamer 407 and carbopol 934P exhibited highest gel strength. On the other hand F1 was made of lower levels of both the polymers. Clearly the gel strength was directly dependent on the levels of constituting polymers.

Ex vivo mucoadhesive strength

The results in Table 2 revealed that amount of carbopol $934 \mathrm{P}$ influenced mucoadhesive strength. On increasing the concentration of carbopol $934 \mathrm{P}$, mucoadhesive strength increased due to wetting and swelling of carbopol $934 \mathrm{P}$ that permitted intimate contact with nasal tissue. As described in literature, interpenetration of bioadhesive carbopol $934 \mathrm{P}$ chains with mucin molecules leads to entanglement and formation of weak chemical bonds between entangled chains. Furthermore, the carboxyl group of carbopol 934P undergoes hydrogen bonding with sugar residues in oligosaccharide chain of mucin glycoprotein in mucus membrane, resulting in strong network between polymer and mucus membrane. The strength of the 
mucoadhesive force, is a prominent determinant of retentivity of the formulation in the nasal cavity and hence absorption across mucosal tissues. [27]

\section{In vitro release}

The in vitro release profiles of mucoadhesive in-situ nasal gels of REP (Fig. 3) were compared to the release profile of pure drug. REP depicted a cumulative drug release (CDR) of only $20.35 \%$ at the end of $12 \mathrm{~h}$ which may due to poor solubility of the drug in the release media that resulted in the poor dissolution of the drug. The CDR in $12 \mathrm{~h}$ from all the formulations designed using REP-PVP K30 dispersion was higher than pure drug indicating solubility limited dissolution of the drug. Consequently, the CDR ranged between $60.14 \pm$ 0.65 and $82.25 \pm 0.90 \%$, almost 3-4 folds higher than pure drug formulation. Amongst these formulations, F3 revealed maximum CDR of $82.25 \%$ in $12 \mathrm{~h}$ followed by F4, F6, F5, F2 and F1.

\section{Ex vivo permeation}

Ex-vivo permeation profiles of the formulations in phosphate buffer, pH 6.4 (Fig. 4) were used to calculate ex-vivo permeability parameters (Table 3 ). The target flux was calculated as $8.02 \mathrm{mg} / \mathrm{cm}^{2} / \mathrm{h}$ and pure drug was not able to reach the target flux. Though the formulations designed using REP solid dispersion, the flux was higher than pure drug formulation but except for formulation F3, none could achieve the target flux. Higher flux values of formulations F1- F6 than pure drug is attributable to the permeability affecting property of PVP K 30 . Amongst all, formulation F3 composed of high levels of both poloxamer 407 and carbopol $934 \mathrm{P}$ showed highest release and correspondingly highest permeation of drug $(78.73 \pm$ $0.37 \%$ ) clearly demonstrating the role of levels of constituting polymers. F3 by virtue of its highest carbopol levels presented strongest mucoadhesion favouring permeation and consequently release.

The study also depicts the importance of $\mathrm{Ca}^{++}$in enhancing the permeation of REP across the mucosa. The anionic polymer carbopol is reported to demonstrate permeation enhancing properties by its ability to bind to the $\mathrm{Ca}^{2+}$ of the nasal mucosa. With the increase in carbopol concentration, the concentration of $\mathrm{COO}^{-}$group is increased which leads to conformational changes in the polymeric chain. The polymer chain decoils due to electrostatic repulsion of the $\mathrm{COO}^{-}$ resulting in relaxation of polymeric network. At this stage, the drug is rapidly dissolved and diffused from the gels due to extensive swelling of the ionized carbopol. [23] Correspondingly, highest drug permeation was shown by F3 made of $1 \% \mathrm{w} / \mathrm{v}$ carbopol (highest levels) and the least permeation was shown by F1 (of $0.25 \% \mathrm{w} / \mathrm{v}$ carbopol; lowest level). However, the presence of poloxamer in the gel tends to retard the release rate of drug due to reduction in dimensions of water channels. [28] The polymeric surfactant poloxamer 407 , forms micelles in aqueous phase, and the incorporated drug may be released via diffusion through the gel matrix. Both the drug release and permeation can also be affected by the gel viscosity, aqueous channel's size and drug distribution between the micelles and the aqueous phase. ${ }^{[29]}$ The increase in poloxamer causes slight increase in viscosity and hence slightly decreases the release REP from the gel and the permeation. ${ }^{[30]}$ However, in our case the effect of poloxamer concentration was counteracted by the presence of carbopol 934P.

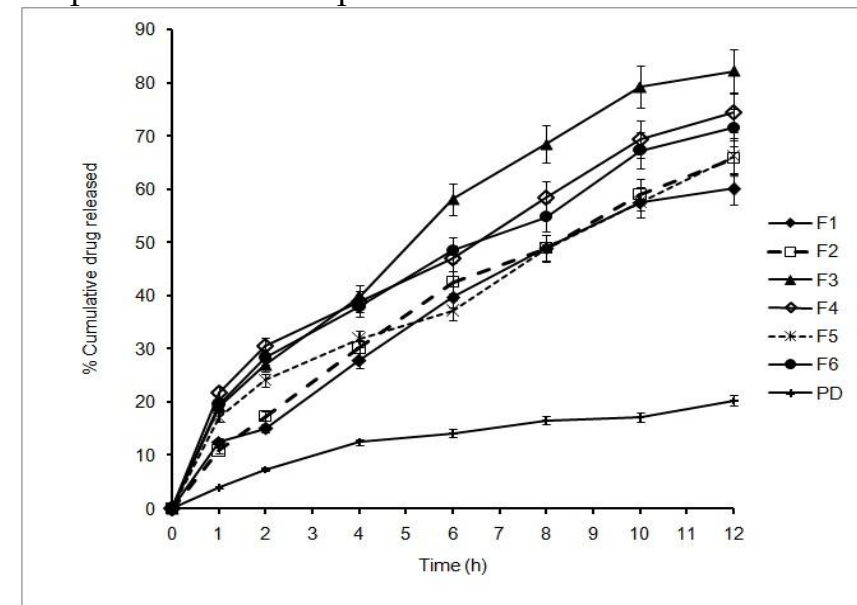

Fig. 3: In vitro release profiles of REP from mucoadhesive in-situ nasal gels compared with pure drug (PD)

The permeability coefficient for pure drug was 1.68 $\mathrm{cm} / \mathrm{h}$ and for F1-F6 it ranged between $2.02-5.01 \mathrm{~cm} / \mathrm{h}$. The permeability coefficient was higher for the gels containing solid dispersion than the gel of pure drug REP and is co-relatable to the state of drug in the gel and the formulation variables. The drug in solubilized form exhibited higher permeability coefficient than pure drug. Furthermore, formulation F3 composed of highest levels of constituting polymers and highest flux value exhibited highest permeability. The ex vivo permeation data when modelled exhibited Higuchi kinetics for pure drug, F2 and F6.On the other hand F1, F3,F4 and F5 best fitted zero order model. The variation in kinetics is not explainable.

\section{Data analysis}

The ex vivo permeation plot of $\mathrm{F} 3$ was compared against the plots pure drug and fitted to various kinetic models to evaluate the role of solid dispersion in enhancing permeation across nasal mucosa. F3 was able to sustain the release and achieve $78.7 \pm 0.37 \%$ in $12 \mathrm{~h}$ (Fig. 4) that was comparable to CDP of $18.84 \pm 1.05 \%$ achieved by pure drug. This clearly indicates that the gel matrix did not impede the release of solid dispersion loaded in situ gel from F3 (Table 3). Compared to pure drug F3 exhibited 2.94 folds increase in ex-vivo permeation across goat nasal mucosa that was significantly higher than $(P<0.05)$ pure drug suspension indicating the efficiency solid dispersion loaded in situ gel. On fitting the data to various kinetic models, F3 followed zero order kinetics (Table 3) which means that flux was independent of amount of drug permeated at various time points and showed maximum coefficient of permeability $(2.02 \mathrm{~cm} / \mathrm{h})$ as compared to pure drug. 

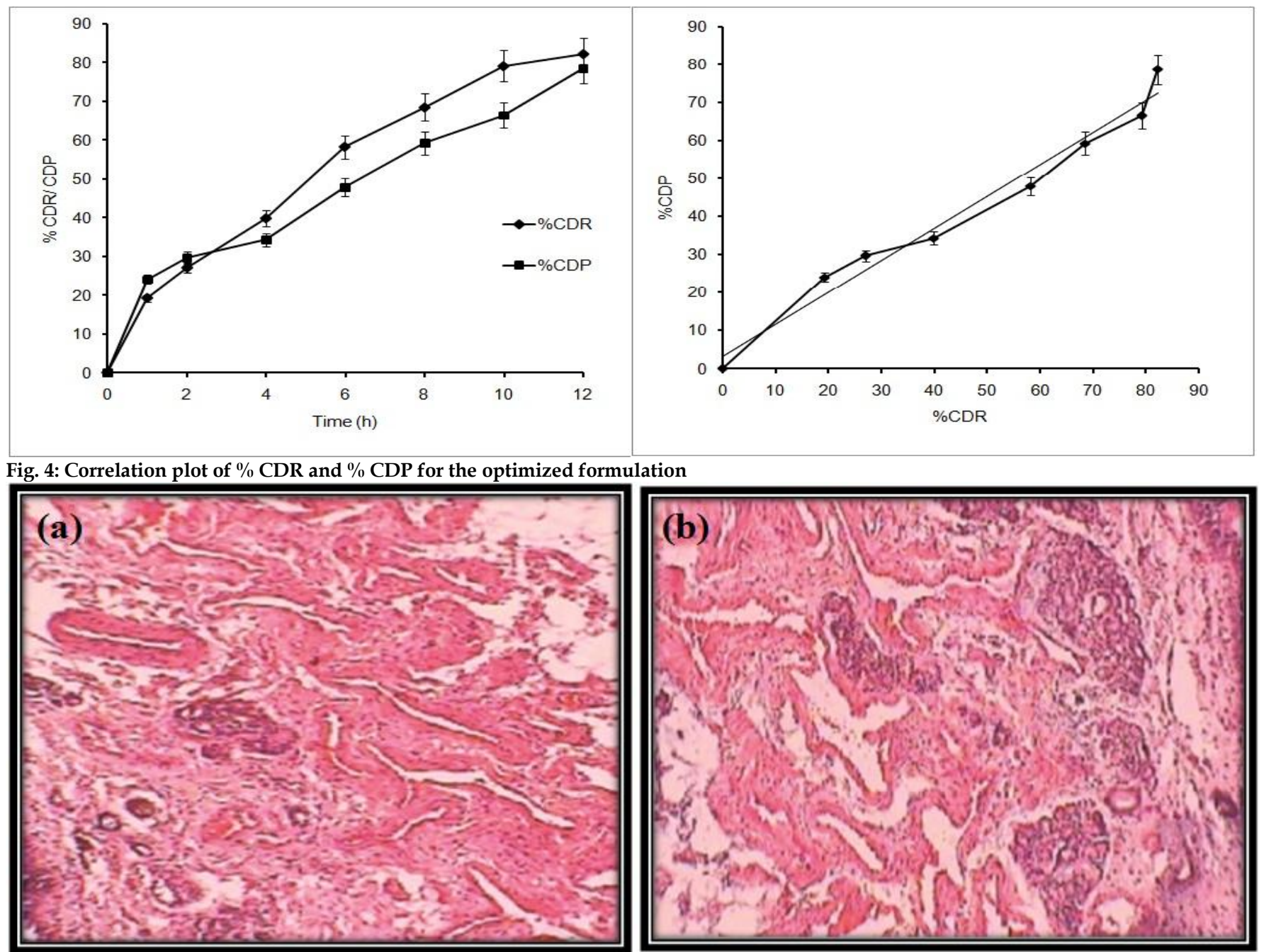

Fig. 5: Histological micrographs of nasal mucosa after treatment with optimized nasal gel (b) compared to control (a)

\section{Selection of optimized gel}

The selection of optimized formulation was done on the basis of evaluation parameters including gelling temperature, $\mathrm{pH}$, gel strength, ex-vivo mucoadhesive strength and ex-vivo permeation study. Considering the mentioned parameters F3 was selected as the optimized formulation with least gelling temperature of $29.42^{\circ} \mathrm{C}$. F3 was found to exhibit the maximum mucoadhesive strength of 6434.4 dynes $/ \mathrm{cm}^{2}$ along with maximum drug permeation of $78.7 \%$. The optimized formulation F3 was further subjected to histological and stability study.

\section{Histology}

Photomicrograph of goat nasal mucosa was observed for histological changes after permeation studies and was compared with the control. As shown in Fig. 5 neither cell necrosis nor removal of the epithelium from the nasal mucosa was observed after permeation of the gel, consequently there were no alterations in epithelium layer, and basal membrane when compared with the control mucosa. Hence, it can be concluded that the gel formulation can be safely administered via nasal route.

\section{Stability}

The optimized formulation (F3) exhibited no significance difference in the clarity, $\mathrm{pH}$, drug content and ex-vivo permeation characteristics at $0,1,2$ and 3 rd month. Hence the formulation can be concluded as a stable formulation.

Solubility of repaglinide was successfully increased by making its solid dispersion with PVP K 30. In situ nasal gels containing solid dispersion of drug reached the target flux easily. The optimized formulation F3 containing 30\% Poloxamer 407, 1\% Carbopol 934 P had sufficient mucoadhesive property to ensure longer residence time at the site of application and was able to permeate $78.7 \%$ drug through goat nasal mucosa within 12 hour. Controlled release of the incorporated drug was achieved, which ensured better patient compliance and higher therapeutic efficacy.

\section{REFERENCES}

1. Illum L. Nasal drug delivery: new developments and strategies. Drug Discovery Today 2002; 23(7): 1184-9.

2. Hirlekar RS. Momin AM. Advances in Drug Delivery from Nose to Brain: An Overview. Curr Drug Ther. 2018; 13:4-24.

3. Chien YW. Nasal drug delivery and delivery system In: Novel drug delivery systems. 2nd ed. Marcel Dekker Inc; 1992. p. 229-268.

4. Chatterji B. Nose to Brain Delivery: Recent update. J Formul Sci Bioavail. 2017;1: 105-111.

5. Huang Y, Dai W-G. Fundamental aspects of solid dispersion technology for poorly water-soluble drugs. Acta Pharm Sinica B. 2014;4: 18-25. 
6. Sean C S, Martindale: The complete drug reference. 36th ed. Pharmaceutical press; 2009. p. 457-458.

7. El-Houssieny BM, Wahman L, Arafa NM. Bioavailability and biological activity of liquisolid compact formula of repaglinide and its effect on glucose tolerance in rabbits. Biosci Trends. 2010; 4:17-24.

8. Tripathi KD. Essentials of Pharmacology. 6th ed. Jaypee brother's medical publishers; 2007. p. 266-269.

9. Purvis T, Mattucci EM, Crisp TM, et al. Rapidly dissolving repaglinide powders produced by the ultra-rapid freezing process. AAPS PharmSciTech. 2007; 8(2):E52-E60.

10. Dhanalekshmi UM, Poovia G, Reddy PN, In vitro observation of repaglinide engineered polymeric nanoparticles. Digest J Nanomat Biostruct. 2012; 7:1-18.

11. Rao MEB, Swain S, Patra CN, et al., Development and in vitro evaluation of floating multiparticulate system of repaglinide. FABAD J Pharm Sci. 2011; 36:75-92.

12. Joshi J, Bhakuni L, Kumar S. Formulation and evaluation of solid matrix tablets of repaglinide. Der Pharmacia Sinica. 2012; 3(5):598-603.

13. Schmolka IR. Artificial skin.1.Preparation and properties of pluronic F-127 gels for the treatment of burns. J Biomed Mater Res. 1972; 6: 571-582.

14. Miller SC, Donovan MD. Effect of poloxamer 407 gel on the miotic activity of pilocarpine nitrate in rabbits. Int J Pharm.1982; 12: 147-152.

15. Choi HG, Jung JH, Ryu JM. Development of in situ gelling and mucoadhesive acetaminophen liquid suppository. Int J Pharm. 1998; 165: 33-44.

16. Garg A, Garg S, Khar RK. Measurement of bioadhesive strength of mucoadhesive buccal tablet: design of an in-vitro assembly. Indian Drugs. 1992; 30: 152-155.

17. Moffat AC, Osselton MD, Widdop B. (Eds.) Clarke's Analysis of Drugs and Poisons (3rd Ed., 2004), Pharmaceutical Press, London, UK, Vol. 1.

18. Akiladevi D, Shanmugapandiyan $\mathrm{P}$, Jebasingh $\mathrm{D}$, et al. Preparation and evaluation of paracetamol by solid dispersion technique. Int J Pharm Pharm Sci. 2011; 3:188-191.
19. Huang Y, Dai W-G, Fundamental aspects of solid dispersion technology for poorly water soluble drugs. Acta Pharm Sinica B. 2014; 4:18-25.

20. Charlton S, Jones NS, Davis SS, et al. Distribution and clearance of bioadhesive formulations from olfactory region in man: effect of polymer type and nasal delivery device. Eur J Pharm Sci. 2007; 30: 295-302.

21. Patel M, Thakkar H, Kasture PV. Preparation and evaluation of thermoreversible formulations of flurazine hydrochloride for nasal delivery. Int J Pharm Pharm Sci. 2010; 2: 116-120.

22. Zhou M, Donovan MD. Intranasal mucociliary clearance of putative bioadhesive polymers gels. Int J Pharm 1996; 135: $115-125$.

23. Majithiya RJ, Ghosh PK, Umrethia ML, et al. Thermoreversible mucoadhesive gel for nasal delivery of sumatriptan. AAPS PharmSciTech 2006; 7(3): E1-E7.

24. Kabanov AV, Batrakova EV, Alakhov VU. Pluronic block copolymers as novel polymer therapeutics for drug and gene deliver. J Control Release. 2002; 82: 189-212.

25. Bromberg LE, Ron ES. Protein and peptide release from temperature-responsive gels and thermogelling polymer matrices. Adv Drug Deliv Rev. 1998; 31: 197-221.

26. Mahajan HS, Shah SK, Surana SJ. In-situ gelling system based on thiolated gellan gum as new carrier for nasal administration of dimenhydrinate. Int J Pharm Sci Nanotech. 2009; 2: 544-550

27. Kunisawa J, Okudaira A, Tsutusmi Y. Characterization of mucoadhesive microspheres for the induction of mucosal and systemic immune responses. Vaccine. 2000; 19:589-594.

28. He C, Kim SW, Lee DS. In situ gelling stimuli-sensitive block copolymer hydrogels for drug delivery. J Control Release. 2008; 127:189-207.

29. Mortensen K, Pedersen JS. Structural study on the micelle formation of poly (ethylene oxide)-poly (propylene oxide)poly (ethylene oxide) triblock copolymer in aqueous solution. Macromolecules.1993; 26: 805-812.

30. Riccia EJ, Lunardi LO, Nanclares DMA, et al. Sustained release of lidocaine from poloxamer 407 gels. Int J Pharm. 2005; 288: 235-244.

HOW TO CITE THIS ARTICLE: Pathak K, Kumar A, Yadav E. Development and Correlation between in vitro Drug Release and in vitro Permeation of Thermally Triggered Mucoadhesive in situ Nasal Gel of Repaglinide PVP K30 Complex. Int. J. Pharm. Sci. Drug Res. 2019; 11(1): 22-30. DOI: 10.25004/IJPSDR.2018.110104 